\title{
Nanostructures, Optical Properties, and Imaging Application of Lead-Sulfide Nanocomposite Coatings
}

\author{
Song Wei Lu"*** and Helmut K. Schmidt* \\ Institut für Neue Materialien, gem. GmbH, Gebäude 43, Im Stadtwald, \\ D-66123, Saarbrücken, Germany
}

Lead-sulfide (PbS) nanocrystals were precipitated in nanocomposite coatings after a pre-photo-polymerization followed by a reaction with $\mathrm{H}_{2} \mathrm{~S}$ gas at $25^{\circ} \mathrm{C}$ for $1 \mathrm{hr}$. PbS nanocrystalline size and optical absorption increased with decreasing UV energy for prephoto-polymerization and increasing concentration. The absorption onset has a large blue shift from $0.41 \mathrm{eV}$ of the corresponding bulk crystal, resulting from the quantum confinement effect. As a result, coating color changes significantly from deep brown to light yellow depending on coating processing conditions. Partially masking the coatings during pre-photo-polymerization gives rise to different colors, leading to imaging applications of PbS nanocomposite coatings.

\section{Introduction}

It is well-known that optical properties of semiconductor quantum dots (QDs) change significantly with reducing nanocrystal size due to their quantum confinement effect, leading to various colors from different QD sizes. ${ }^{1-16}$ This unique size-dependent optical property has resulted in several commercial applications such as optical filter glass and pigments, etc. Among semiconductor QDs, lead-sulfide ( $\mathrm{PbS}$ ) nanocrystal is of particular interest; its optical property and color vary significantly with reducing crystal size. $\mathrm{PbS}$ is an IV-VI semiconductor with a cubic rock salt structure and a narrow band gap of 0.41 $\mathrm{eV}$. Due to its narrow band gap, large Bohr radii of $9 \mathrm{~nm}$, and small effective mass for both the electron and the hole, PbS QDs exhibit a strong quantum confinement

Partially supported by the Ministry for Research and Culture of the State of Saarland, Germany

*Member, American Ceramic Society

${ }^{* *}$ Corresponding author. Present address: PPG Industries, Inc., Glass Technology Center, P.O. Box 11472, Pittsburgh, PA 15238-0472, USA. E-mail: songweilu@hotmail.com. effect compared to the II-VI semiconductors such as CdSe with Bohr radii of $3 \mathrm{~nm}$ for the electron and $0.5 \mathrm{~nm}$ for the hole. As a result, $\mathrm{PbS}$ QDs with narrow size distribution exhibit a fine structured absorption spectrum ${ }^{17-19}$ or blue shift of absorption onset, ${ }^{20}$ and large third-order nonlinear optical susceptibilities. ${ }^{21-24} \mathrm{PbS}$ QDs have wide applications in optical communications, ${ }^{25}$ nonlinear optical devices, ${ }^{21,23,26}$ and infrared (IR) electroluminescence devices, ${ }^{27}$ etc.

Size-tunable $\mathrm{PbS}$ nanocrystals have been synthesized by various methods in recent years. $\mathrm{PbS}$ nanoparticles have been precipitated during heat treatment of Corning Code 6615 glass after melting at $1350^{\circ} \mathrm{C}$ for $3 \mathrm{hr}$ followed by annealing at $450^{\circ} \mathrm{C} .{ }^{28}$ The average crystal size was determined as $8-30 \mathrm{~nm}$ by X-ray diffraction (XRD), depending on the thermal-annealing schedule. Similarly, PbS QDs with different sizes were formed in fluorophosphate glass by controlling annealing time. ${ }^{29}$ Nogami, et al. ${ }^{20}$ investigated $\mathrm{PbS}$ nanoparticle-doped silica glasses by the sol-gel process using lead acetate trihydrate $\left[\mathrm{Pb}\left(\mathrm{CH}_{3} \mathrm{COO}\right)_{2} \cdot 3 \mathrm{H}_{2} \mathrm{O}\right]$ as the raw material. Cubic $\mathrm{PbS}$ 
nanoparticles of 2-10 $\mathrm{nm}$ were obtained by heating the gel-derived glass in $\mathrm{H}_{2} \mathrm{~S}$ gas at various temperatures. Kruis and co-workers ${ }^{30}$ synthesized size-classified $\mathrm{PbS}$ nanoparticles of 3-20 nm using a gas-phase reaction by heating $\mathrm{PbS}$ powders between $600^{\circ} \mathrm{C}$ and $700^{\circ} \mathrm{C}$, leading to mono-dispersed, non-agglomerated, mono-crystalline particles. They found that the band gap of $\mathrm{PbS}$ nanocrystals could be tuned significantly during the sintering process in which particle size varied at different temperatures. ${ }^{31}$ Bakueva, et al. ${ }^{27}$ controlled colloidal $\mathrm{PbS}$ nanocrystal size by capping agents such as oleic acid or octylamine. M. Kowshik, et al. ${ }^{32}$ synthesized PbS nanocrystallites in a microbial system by controlling the solution $\mathrm{pH}$ value. Patel, et al. ${ }^{15}$ synthesized $\mathrm{PbS}$ nanocrystals with different surface capping agents and found that the optical absorption spectra and particle shape depended on the capping agents used. Martucci, et $a l^{33}$ also found that the optical absorption changed significantly with $\mathrm{PbS}$ concentration in zirconia-ormosil coatings. Other techniques to adjust size of semiconductor QDs have already been reported in the literature., ${ }^{94-37}$

Although $\mathrm{PbS}$ nanocrystals have been synthesized by different methods with tunable nanocrystal sizes, their samples were a dispersed solution, coating, or bulk glass with a single range of size distribution, i.e., a single color. For example, the size of $\mathrm{PbS}$ nanocrystal-doped silica glass prepared by the sol-gel process was controlled by gel composition or heat treatment. ${ }^{20}$ As a result, only one color was generated from a heat-treated sample. In this paper, we report a sol-gel synthesis process to precipitate $\mathrm{PbS}$ nanocrystals in sol-gel-derived nanocomposite coatings, during which the crystal size can be controlled by the degree of pre-photo-polymerization, i.e., UV lamp energy used for polymerization, and coating composition. During pre-photo-polymerization, the coatings were covered with a mask to partially block UV exposure, giving rise to different degrees of polymerization on a single sample. Consequently, a vivid image was created in $\mathrm{PbS}$ nanocomposite coatings in which various colors are associated with different sizes of $\mathrm{PbS}$ nanocrystals.

\section{Experimental Procedure}

In order to control PbS nanocrystal size and optical absorption of the nanocomposite coatings, various synthesis parameters have been adjusted, such as sol composition and UV curing energy for pre-photo-polymerization, etc. The $\mathrm{PbS}$ nanocomposite synthesis route includes sol preparation, dip-coating, pre-photo-polymerization, $\mathrm{PbS}$ nanocrystal precipitation by reacting with $\mathrm{H}_{2} \mathrm{~S}$ gas,

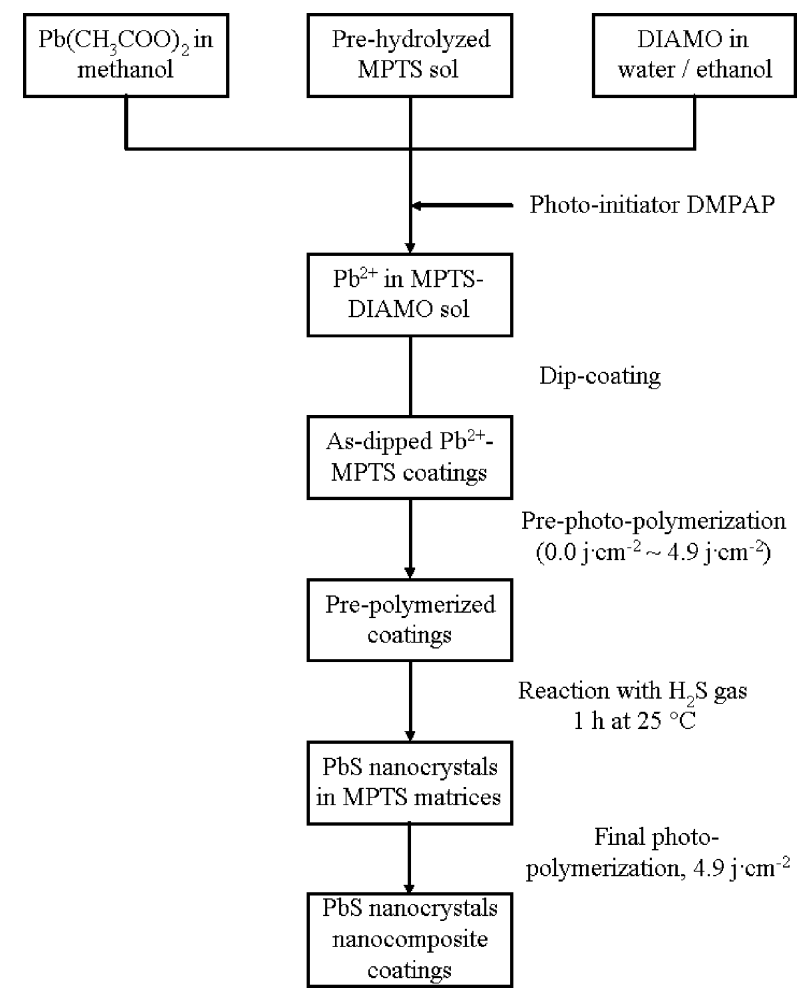

Fig. 1. Schematic representation of synthesis route for PbS nanocomposite coatings.

and final photo-polymerization, as illustrated in Fig. 1. All chemicals were purchased from Sigma-Aldrich Chemie, $\mathrm{GmbH}$, Deisenhofen, Germany and used as received.

\section{Sol Preparation and Dip-Coating}

An amount of $4.88 \mathrm{~g}$ lead acetate $\left[\mathrm{Pb}\left(\mathrm{CH}_{3} \mathrm{COO}\right)_{2}\right]$ was dissolved in $35 \mathrm{~mL}$ methanol, and mixed with 6.807 g 3-(2-aminoethyl)aminopropyl trimethoxysilane (DIAMO), $0.81 \mathrm{~g} \mathrm{H}_{2} \mathrm{O}$, and $50 \mathrm{~mL}$ of $2 \mathrm{M}$ hydrolyzed 3(methacryloyloxy)propyl trimethoxysilane (MPTS) sol, which was pre-hydrolyzed at $50^{\circ} \mathrm{C}$ for $24 \mathrm{hr}$ with an MPTS to $\mathrm{H}_{2} \mathrm{O}$ molar ratio of $1: 1$.5. In addition, $0.256 \mathrm{~g} 2$,2dimethoxy-2-phenylacetophenone (DMPAP) was added as photo-initiator with a ratio of double bond $\mathrm{C}=\mathrm{C}$ : DMPAP $=100: 1$ for the purpose of UV polymerization of the MPTS network. The final sol with a viscosity of $2.6 \mathrm{mPa} \cdot \mathrm{s}$ had a molar ratio of MPTS : DIAMO : $\mathrm{Pb}^{2+}=$ $10: 3: 1.5$. Samples made from this sol were referred to as PbS1.5 coatings. Similarly, a sol with a composition of MPTS : DIAMO : $\mathrm{Pb}^{2+}=10: 6: 3$ was also prepared and all samples made from this sol were labeled as PbS3.0 
Table I. UV Energy, UV Lamp Conditions, Sample Moving Speed in the UV Lamp System for PrePhoto-Polymerization, $\mathrm{H}_{2} \mathrm{~S}$ Reaction Conditions, Mean Crystal Size Determined from Line Broadening of XRD Patterns and Absorption Onset Determined from Absorption Spectra of PbS1.5 and PbS3.0 Coatings.

\begin{tabular}{|c|c|c|c|c|c|c|c|}
\hline Sample & Composition & $\begin{array}{l}\text { UV energy for pre- } \\
\text { photo-polymerization } \\
\qquad\left(\mathrm{J} \cdot \mathrm{cm}^{-2}\right)\end{array}$ & $\begin{array}{l}\text { UV lamp } \\
\text { condition }\end{array}$ & $\begin{array}{c}\text { Sample } \\
\text { moving speed } \\
\left(\mathrm{m} \cdot \mathrm{min}^{-1}\right)\end{array}$ & $\begin{array}{c}\mathrm{H}_{2} \mathrm{~S} \text { reaction } \\
\text { conditions }\end{array}$ & $\begin{array}{l}\text { Crystalline } \\
\text { size by XRD } \\
(\mathrm{nm})\end{array}$ & $\begin{array}{c}\text { Absorption } \\
\text { onset } \\
(\mathrm{eV})\end{array}$ \\
\hline & & 0.0 & - & - & $25^{\circ} \mathrm{C}$ for $1 \mathrm{hr}$ & 6.0 & 1.08 \\
\hline \multirow[t]{4}{*}{$\mathrm{PbS} 1.5$} & 10MPTS-3DIAMO- & 0.35 & One lamp 50\% & 4.0 & $25^{\circ} \mathrm{C}$ for $1 \mathrm{hr}$ & 4.5 & 1.27 \\
\hline & $1.5 \mathrm{PbS}$ & 1.1 & One lamp 50\% & 1.0 & $25^{\circ} \mathrm{C}$ for $1 \mathrm{hr}$ & 2.9 & 1.85 \\
\hline & & 4.9 & Two lamp $100 \%$ & 1.0 & $25^{\circ} \mathrm{C}$ for $1 \mathrm{hr}$ & - & 2.39 \\
\hline & & 0.0 & - & - & $25^{\circ} \mathrm{C}$ for $1 \mathrm{hr}$ & 8.3 & 0.91 \\
\hline \multirow[t]{3}{*}{ PbS3.0 } & 10MPTS-6DIAMO- & 0.35 & One lamp 50\% & 4.0 & $25^{\circ} \mathrm{C}$ for $1 \mathrm{hr}$ & 6.2 & 1.08 \\
\hline & $3 \mathrm{PbS}$ & 1.1 & One lamp 50\% & 1.0 & $25^{\circ} \mathrm{C}$ for $1 \mathrm{hr}$ & 5.8 & 1.11 \\
\hline & & 4.9 & Two lamp 100\% & 1.0 & $25^{\circ} \mathrm{C}$ for $1 \mathrm{hr}$ & 2.8 & 1.90 \\
\hline
\end{tabular}

coatings. Sol-gel-derived coatings containing $\mathrm{Pb}^{2+}$ ions were dip-coated from the above sols on soda-lime-silicate glasses with a withdraw speed of $6 \mathrm{~mm} \cdot \mathrm{s}^{-1}$.

\section{Pre-Photo-Polymerization}

The as-dipped coatings containing $\mathrm{Pb}^{2+}$ ions were partially pre-photo-polymerized at room temperature under different UV energies in a Beltron UV system with strong lines located at $365 \mathrm{~nm}, 405 \mathrm{~nm}$, and $435 \mathrm{~nm}$ (Beltron, GmbH, Rödermark, Germany). The UV energy was controlled by the irradiation time, i.e., sample moving speed in the UV lamp system, and the percentage of the lamps. Table I shows the UV energy, UV lamp conditions and sample moving speed in the UV lamp system for pre-photo-polymerization of all samples.

\section{Formation of PbS Nanocrystals and Final Polymerization}

The partially photo-polymerized coatings containing $\mathrm{Pb}^{2+}$ ions were reacted with excess amount of $\mathrm{H}_{2} \mathrm{~S}$ gas at room temperature in a sealed $1 \mathrm{~L}$ glass container for $1 \mathrm{hr}$ to precipitate $\mathrm{PbS}$ nanocrystals (Table I). All coatings were then cured by $4.9 \mathrm{~J} \cdot \mathrm{cm}^{-2} \mathrm{UV}$ in the Beltron UV lamp system for a final full polymerization.

\section{Characterization}

High-resolution transmission electron microscopy (HRTEM) investigations were performed using a Philips CM 200 FEG transmission electron microscopy with a Schottky-type field emission gun (FEG) generating the beam energy up to $200 \mathrm{KeV}$. Film thickness was measured by means of a Tencor P-10 surface profiler instrument with a scanning speed of $0.5 \mu \mathrm{m} \cdot \mathrm{min}^{-1}$. Optical absorption spectra were recorded at room temperature using an Omega 20 UV-VIS-NIR spectrophotometer (Bruins Instruments, GmbH, Puchheim, Germany) from 190 $\mathrm{nm}$ to $1000 \mathrm{~nm}$. The scanning speed was taken as 600 $\mathrm{nm} \cdot \mathrm{min}^{-1}$. All optical absorption spectrum measurements were referred to air. XRD measurements were carried out in a Siemens D 500 diffractometer by $\mathrm{Cu} \mathrm{K}_{\alpha}$ using $2 \theta$ scanning method from $2 \theta=20^{\circ}-60^{\circ}$ with a step of $0.02^{\circ}$ and an incident angle of $1^{\circ}$. Viscosity was measured using a Physica Rotational Viscometer Z1 DIN double-gapsystem.

\section{Results and Discussion}

\section{Nanostructures}

Nanostructures of $\mathrm{PbS}$ nanocrystals in nanocomposite coatings were investigated in detail by means of HRTEM and XRD. Fig. 2 shows HRTEM contrast images of PbS nanocrystals in PbS1.5 and PbS3.0 coatings without prephoto-polymerization followed by a reaction with $\mathrm{H}_{2} \mathrm{~S}$ gas at $25^{\circ} \mathrm{C}$ for $1 \mathrm{hr}$. The insert in Fig. $2 \mathrm{a}$ is an individual nanoparticle from $\mathrm{PbS} 1.5$ coatings. The images show that $\mathrm{PbS}$ nanocrystals in nanocomposite coatings have a narrow size distribution and are uniformly distributed in the coatings. Both spherical and elliptical $\mathrm{PbS}$ nanoparticles are found in these coatings. The elliptical particles, either prolate (i.e., rod-like) or oblate (i.e., disk-like), have an approximate width to length ratio of about $1: 2$. How- 

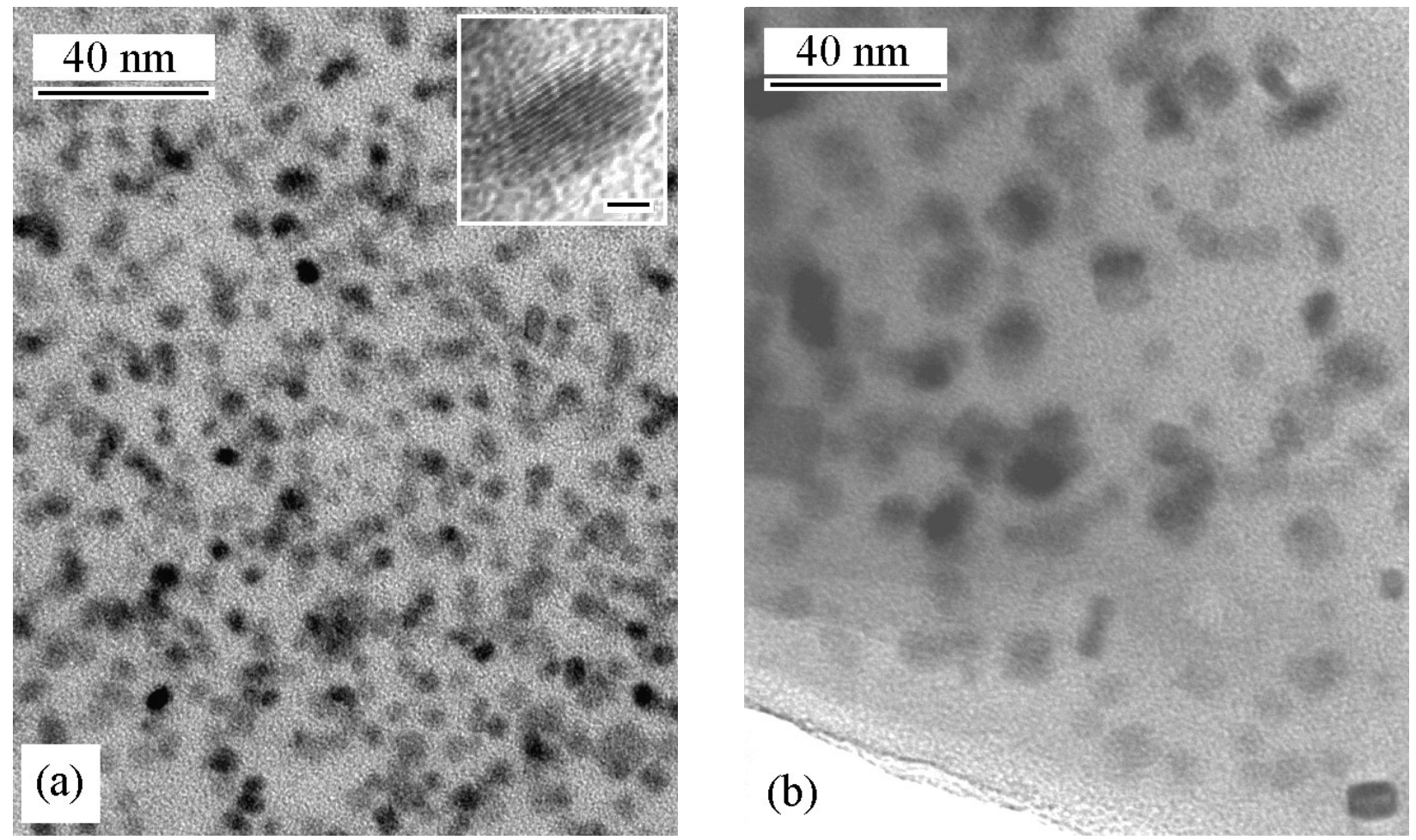

Fig. 2. HRTEM contrast images of PbS nanocrystals in (a) PbS1.5 coatings and (b) PbS3.0 coatings, both without pre-photopolymerization. The insert in (a) shows an individual PbS nanocrystal with lattice fringe from PbS1.5 coatings. Bar in the insert: $2 \mathrm{~nm}$.

ever, no needle-like particle is observed. The crystalline lattice fringe of $\mathrm{PbS}$ nanocrystals in PbS1.5 coatings (Fig. 2a insert) reveals that the lattice constant is $0.297 \mathrm{~nm}$ for (200) face, which is in good agreement with the standard lattice from JCPDS No. 5-592 of cubic PbS (galena) crystals. The Gaussian distributions of statistically estimated particle size from 180 particles in Fig. 2a of PbS1.5 coatings and from 110 particles of four images including Fig. $2 \mathrm{~b}$ of PbS3.0 coatings are shown in Fig. 3. The mean $\mathrm{PbS}$ nanoparticle size is $6.0 \pm 0.8 \mathrm{~nm}$ for PbS1.5 coatings and $7.9 \pm 1.8 \mathrm{~nm}$ for PbS3.0 coatings, both without prephoto-polymerization. It shows that $\mathrm{PbS}$ nanocrystals in PbS3.0 coatings are larger than those in PbS1.5 coatings. In addition, the size distribution in PbS3.0 coatings is broader than that in $\mathrm{PbS} 1.5$ coatings. Although the $\mathrm{PbS}$ concentration in PbS3.0 coatings is double that of PbS1.5 coatings, the number of $\mathrm{PbS}$ nanoparticles in $\mathrm{PbS} 3.0$ coatings may not be necessary more than that in $\mathrm{PbS} 1.5$ coatings, since the PbS1.5 coatings have a smaller mean nanoparticle size than PbS3.0 coatings.

Fig. 4 presents XRD patterns of $\mathrm{PbS}$ nanocrystals in $\mathrm{PbS} 1.5$ and $\mathrm{PbS} 3.0$ coatings on slide glasses with differ- ent degrees of pre-photo-polymerization. As shown in Fig. 4, all samples are identified as cubic $\mathrm{PbS}$ crystals since their XRD patterns match well with PbS (galena) JCPDS card No. 5-592 (vertical lines), except for spectrum 1 in Fig. 4a. This is consistent with HRTEM results that the crystalline lattice constant is determined as $0.297 \mathrm{~nm}$ for (200) of cubic PbS crystals. XRD patterns of these coatings show that the diffraction peak intensity increases with decreasing UV energy for pre-photo-polymerization. There is no noticeable peak for $\mathrm{PbS} 1.5$ coatings pre-photo-polymerized with UV energy of $4.9 \mathrm{~J} \cdot \mathrm{cm}^{-2}$ (Fig. 4a, spectrum 1). The XRD peak starts to emerge after decreasing the UV energy from 4.9 to $1.1 \mathrm{~J} \cdot \mathrm{cm}^{-2}$. The peaks are very broad when using UV energy of $0.35 \mathrm{~J} \cdot \mathrm{cm}^{-2}$ and become narrow and sharp for samples without pre-photo-polymerization. For example, for the (200) peak at $2 \theta=30.08^{\circ}$ in $\mathrm{PbS} 3.0$ coatings, its full width at half-maximum (FWHM) is $2.56^{\circ}$ for a coating pre-photo-polymerized with a UV energy of $4.9 \mathrm{~J} \cdot \mathrm{cm}^{-2}, 1.68^{\circ}$ with a UV energy of $1.1 \mathrm{~J} \cdot \mathrm{cm}^{-2}, 1.50^{\circ}$ with a UV energy of $0.35 \mathrm{~J} \cdot \mathrm{cm}^{-2}$, and $1.10^{\circ}$ without pre-photo-polymerization. This indicates the growth of $\mathrm{PbS}$ nanocrystals for samples with reduc- 


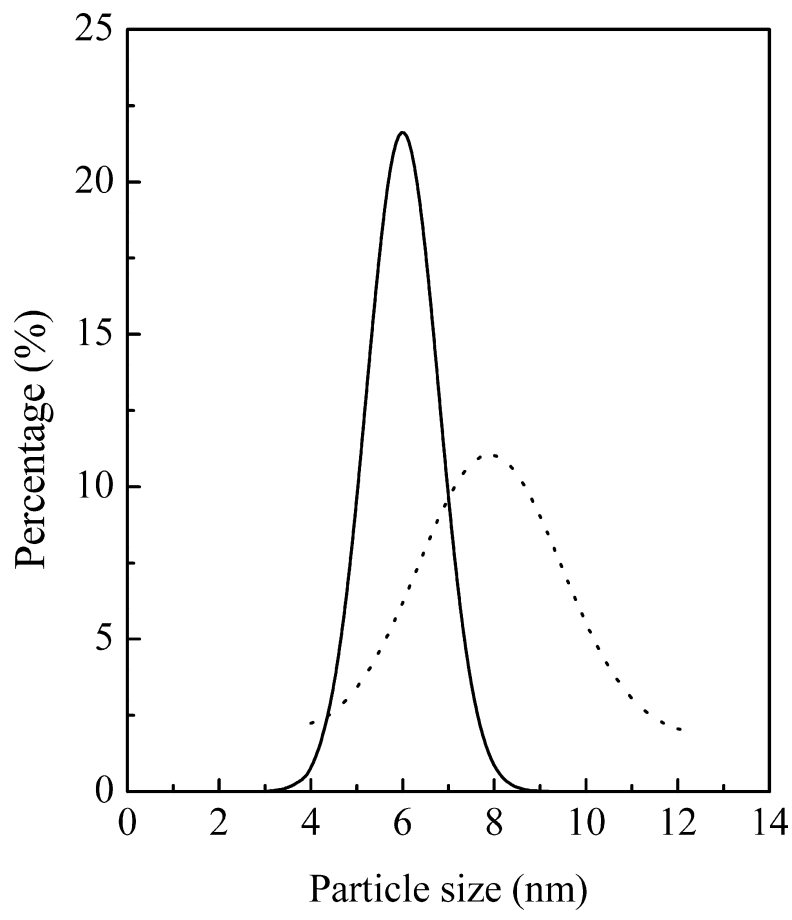

Fig. 3. Statistical estimations of nanoparticle size from about 180 particles from PbS1.5 coatings in Fig. $2 a$, and from about 110 particles from PbS3.0 coatings in four HRTEM images including Fig. 2b. The mean particle size is $6.0 \pm 0.8 \mathrm{~nm}$ for PbS1.5 coatings (solid line) and $7.9 \pm 1.8 \mathrm{~nm}$ for PbS3.0 coatings (dotted line).

ing UV energy during pre-photo-polymerization.

From these XRD patterns in Fig. 4, the mean crystallite size (D) can be calculated by the X-ray line broadening, using Scherrer's equation:

$$
\mathrm{D}=57.3 \mathrm{k} \lambda /(\beta \cos \theta)
$$

where $\mathrm{k}$ is the geometric factor (normally $\mathrm{k}=1.0$ for cubic PbS particles), $\lambda$ the X-ray wavelength (for $\mathrm{Cu} \mathrm{k}_{\mathrm{a}}, \lambda=$ $0.154056 \mathrm{~nm}$ ), $\beta$ the FWHM of the diffraction line broadening in degree, and $\theta$ the peak position in degree. The estimated error of the calculated diameter for nanocrystals is $15 \%$ from Scherrer's equation. Table I also lists the calculated mean crystalline size from line broadening of all XRD peaks for both PbS1.5 and PbS3.0 coatings. The calculated mean crystal sizes are based on all peaks from one pattern. The calculation shows that crystallite sizes determined by XRD are in good agreement with the particle sizes determined by HRTEM for both PbS1.5 and $\mathrm{PbS} 3.0$ coatings without pre-photo-polymerization. Here we assume that these nanoparticles are mono-crystalline particles.
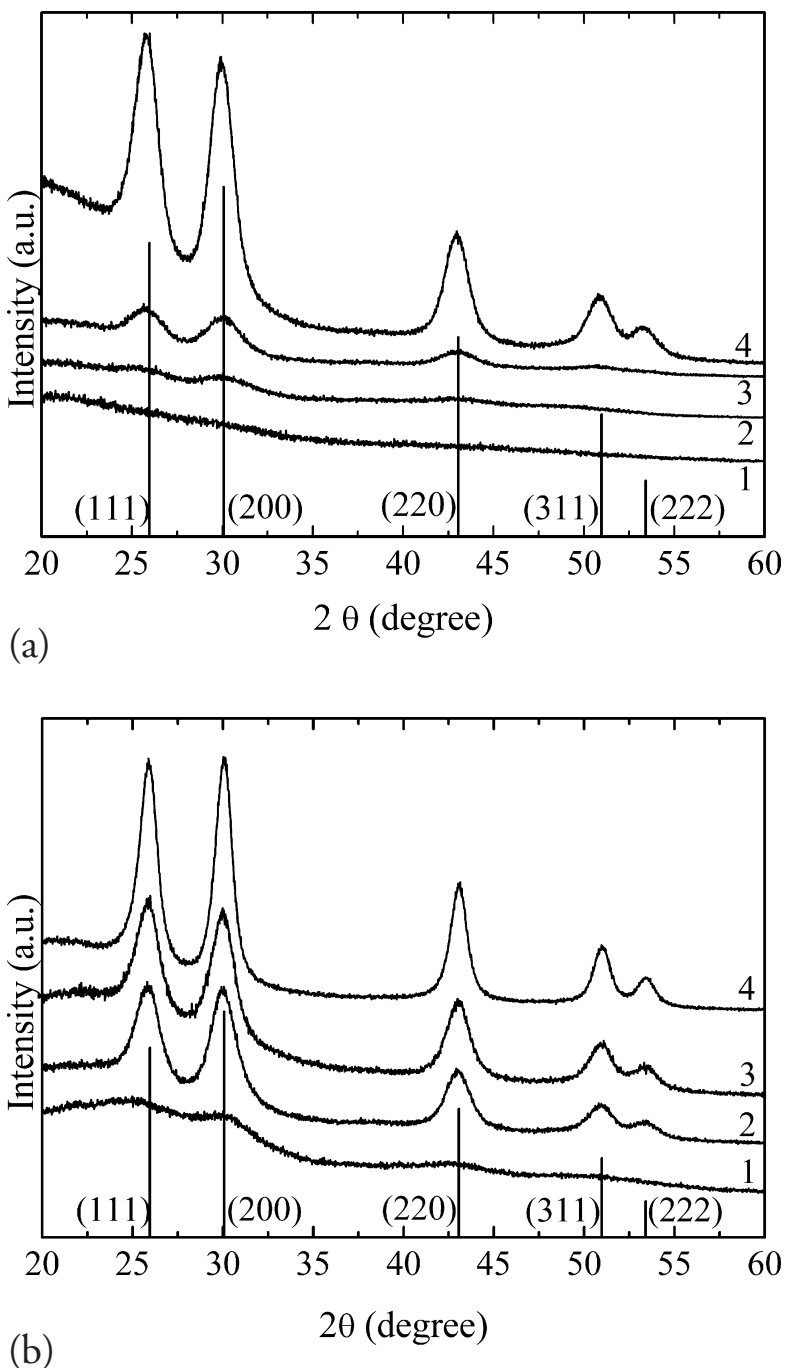

Fig. 4. (a) XRD patterns of PbS nanocrystals in PbS1.5 coatings on slide glasses with different $U V$ energies for pre-photo-

polymerization: (1) UV $4.9 \mathrm{~J} \cdot \mathrm{cm}^{-2}$, no peak; (2) UV $1.1 \mathrm{~J} \cdot \mathrm{cm}^{-2}$, mean size $2.9 \mathrm{~nm}$; (3) UV $0.35 \mathrm{~J} \cdot \mathrm{cm}^{-2}$, mean size $4.5 \mathrm{~nm}$; and (4) without pre-photo-polymerization, mean size $6.0 \mathrm{~nm}$. (b) XRD patterns of PbS nanocrystals in PbS3.O coatings on slide glasses with different $U V$ energies for pre-photo-polymerization: (1) UV $4.9 \mathrm{~J} \cdot \mathrm{cm}^{-2}$, estimated size less than $2.8 \mathrm{~nm}$; (2) UV 1.1 $\mathrm{J} \cdot \mathrm{cm}^{-2}$, mean size $5.8 \mathrm{~nm}$; (3) UV $0.35 \mathrm{~J} \cdot \mathrm{cm}^{-2}$, mean size 6.2 nm; (4) coatings without UV pre-photo-polymerization, mean size $8.3 \mathrm{~nm}$.

In Table I, the crystallite size from both coating compositions decreases with increasing UV energy used for pre-photo-polymerization. For example, for the PbS3.0 coatings, the mean crystallite size decreases from $8.3 \mathrm{~nm}$ without pre-photo-polymerization to $6.2 \mathrm{~nm}$ with 0.35 
$\mathrm{J} \cdot \mathrm{cm}^{-2} \mathrm{UV}$ treatment, $5.8 \mathrm{~nm}$ with $1.1 \mathrm{~J} \cdot \mathrm{cm}^{-2}$, and 2.8 $\mathrm{nm}$ with $4.9 \mathrm{~J} \cdot \mathrm{cm}^{-2}$. The reason for this effect might be interpreted with respect to the network solidity of the nanocomposite coatings. After using high UV energy of $4.9 \mathrm{~J} \cdot \mathrm{cm}^{-2}$ for pre-photo-polymerization, the coating network is completely solidified. Lead ions are anchored by amino groupings from DIAMO, which has been polymerized with an MPTS solid matrix during photo-polymerization. The homogeneous distribution of $\mathrm{Pb}^{2+}$ ions in such a solid matrix leads to the difficulty for them to diffuse from place to place in order to form large particles. On the other hand, with less UV energy for prephoto-polymerization, such as $0.35 \mathrm{~J} \cdot \mathrm{cm}^{-2}$ or even without UV pre-photo-polymerization, the network of the MPTS matrix is not completely formed, resulting in more spaces for diffusion of $\mathrm{Pb}^{2+}$ ions in the growth (such as Ostwald ripening and/or agglomeration) of $\mathrm{PbS}$ crystallites. This was confirmed by the rapid color change during the reaction with $\mathrm{H}_{2} \mathrm{~S}$ gas from samples without UV pre-photo-polymerization, compared to very slow color change during the reaction with $\mathrm{H}_{2} \mathrm{~S}$ gas from samples with $4.9 \mathrm{~J} \cdot \mathrm{cm}^{-2} \mathrm{UV}$ pre-photo-polymerization. In addition, the diffusion rate of $\mathrm{H}_{2} \mathrm{~S}$ gas in an incompletely polymerized network may be higher than that in a fully polymerized MPTS network. The different degrees of MPTS network solidification after exposing to different UV energies are in good agreement with the literature; a gradient structure material from a homogeneous system of monomers can be synthesized by UV photo-polymerization thanks to the decay of UV light intensity through sample thickness of $5 \mathrm{~mm}^{38}$

As discussed earlier, $\mathrm{PbS}$ nanocrystals with different shapes have been observed (Fig. 2). This can be interpreted with the growth of $\mathrm{PbS}$ nanocrystals. Gacoin, et al. ${ }^{39}$ and Ricolleau, et al. ${ }^{40}$ investigated the evolution of $\mathrm{PbS}$ nanocrystals in a methanol solution without a stabilizer. They found that $1 \mathrm{~min}$ after precipitation in methanol, PbS QDs were fiber-like nanocrystals $(2.5 \times 25 \mathrm{~nm})$ or platelet nanocrystals. After $16 \mathrm{~min}$ they became nearly cubic nanocrystals with an average size of $13 \mathrm{~nm}$. The growth of $\mathrm{PbS} \mathrm{QDs}$ in PbS1.5 and PbS3.0 coatings may not be the same as PbS QDs in a methanol solution. In the present experiment, $\mathrm{PbS} \mathrm{QDs}$ are capped by the $-\mathrm{NH}$ and $-\mathrm{NH}_{2}$ groups from DIAMO, and the diffusion of $\mathrm{Pb}^{2+}$ ions is limited by the partially solidified MPTS network. The precipitation of $\mathrm{PbS}$ QDs involves nucleation of $\mathrm{PbS}$ nuclei after initial reaction of $\mathrm{Pb}^{2+}$ ions in the network with $\mathrm{H}_{2} \mathrm{~S}$ gas. During the next step, the $\mathrm{PbS}$ nuclei grow to $\mathrm{PbS}$ QDs while $\mathrm{Pb}^{2+}$ ions in the surround- ing network continue to react with excess $\mathrm{H}_{2} \mathrm{~S}$ gas. $\mathrm{Pb}^{2+}$ ions may diffuse to nuclei sites depending on the degree of pre-photo-polymerization. The final growth of $\mathrm{PbS}$ QDs is then completed when removing the samples from $\mathrm{H}_{2} \mathrm{~S}$ gas atmosphere. Thus, the shape of $\mathrm{PbS}$ nanocrystals may also depend on the degree of pre-photo-polymerization and the reaction conditions with $\mathrm{H}_{2} \mathrm{~S}$ gas. The presence of spherical or elliptical $\mathrm{PbS}$ nanocrystals and the absence of needle-like nanocrystals indicate that $\mathrm{PbS}$ nanocrystals already pass the initial nuclei stage and reach an equilibrium crystallization stage without agglomeration.

\section{Linear Optical Properties}

These PbS nanocomposite coatings with different degrees of pre-photo-polymerization and different compositions yielded different colors from deep brown to light yellow. Fig. 5 shows the absorption spectra of $\mathrm{PbS}$ nanocrystals in PbS1.5 and PbS3.0 nanocomposite coatings with a thickness of $1.0 \mu \mathrm{m}$ after different degrees of prephoto-polymerization using UV energy from $0.0 \mathrm{~J} \cdot \mathrm{cm}^{-2}$ (i.e., without UV curing) to $4.9 \mathrm{~J} \cdot \mathrm{cm}^{-2}$ followed by reacting with $\mathrm{H}_{2} \mathrm{~S}$ gas at $25^{\circ} \mathrm{C}$ for $1 \mathrm{hr}$. The reference samples of MPTS coatings without PbS nanocrystals after prephoto-polymerization and reaction with $\mathrm{H}_{2} \mathrm{~S}$ gas, and asdipped MPTS coatings with $\mathrm{Pb}^{2+}$ ions are plotted together for comparison. The absorption onset is determined by a method for PbS QDs described by Nogami, et al. ${ }^{20}$ by extrapolating the absorbance to zero, as listed in Table I.

From the above absorption spectra (Fig. 5), the absorbance of these PbS1.5 and PbS3.0 coatings decreases with increasing UV curing energy, and the absorption onset has a blue shift with increasing UV energy for prephoto-polymerization. The increase of absorbance from samples (curves 1-4 in Fig. 5) in both coatings is apparently caused by the formation of $\mathrm{PbS}$ nanocrystals, compared to reference samples. The reason for decreasing absorbance and the blue shift of the absorption onset is possibly due to a reduction of particle size in these coatings with increasing UV curing energy. For all samples, their absorption onset has a large blue-shift from $0.41 \mathrm{eV}$ of bulk PbS crystal at $300 \mathrm{~K}$ (Table I), resulting from the quantum confinement effect. The size-dependent optical properties have also been observed in $\mathrm{PbS}$ nanocrystaldoped silica glass by the sol-gel process. ${ }^{20}$ However, in comparison to the PbS colloids in a PVA matrix, ${ }^{17,21}$ these coatings exhibit no fine-structured absorption peaks. The absence of the fine-structured absorption peaks can be attributed to the surface disorder as discussed below. 


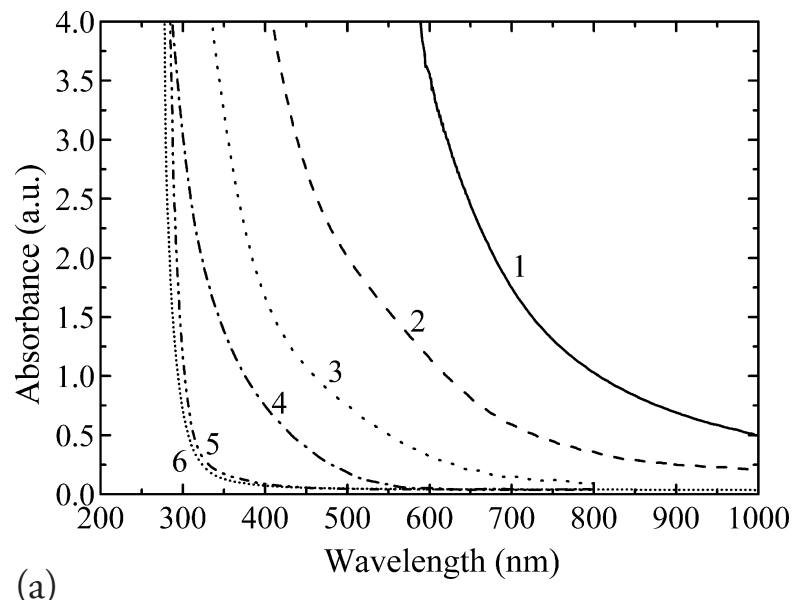

(a)

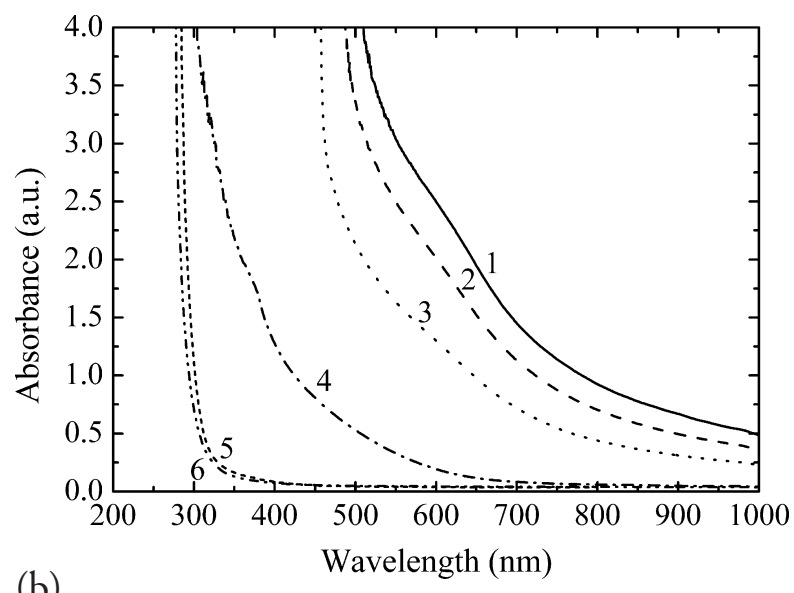

Fig. 5. Absorption spectra of (a) PbS1.5 and (b) PbS3.O coatings on slide glass substrate with different UV energies for pre-photo-polymerization: (1) without pre-photo-polymerization; (2) UV $0.35 \mathrm{~J} \cdot \mathrm{cm}^{-2}$; (3) UV $1.1 \mathrm{~J} \cdot \mathrm{cm}^{-2}$; and (4) UV $4.9 \mathrm{~J} \cdot \mathrm{cm}^{-2}$. The absorption spectra of (5) MPTS-DIAMO coating without $P b S$, and (6) as-dip-coated coating with $\mathrm{Pb}^{2+}$ ions before reacting to $\mathrm{H}_{2} \mathrm{~S}$ gas are plotted together as references. Coating thickness: $1.0 \mu \mathrm{m}$.

It is known that the quantum confinement effect occurs when the semiconductor QD diameter is less than twice the Bohr radius. The fine-structured absorption peaks and the blue shift of the absorption onset are two indications of the quantum confinement effect. The quantum confinement effect has been confirmed from PbS1.5 and PbS3.0 coatings since their absorption onset has a blue shift from $0.41 \mathrm{eV}$ of bulk PbS crystals at $300 \mathrm{~K}$. According to the literature, ${ }^{22,41}$ the fine-structured absorption spectrum caused by the quantum confinement ef- fect depends on mean particle size, size distribution, and surface disorder. The presence of the surface disorder on nanoparticles can weaken the fine-structured absorption peak. ${ }^{41}$ Although the estimated mean size of $\mathrm{PbS}$ nanocrystals is still much less than double the Bohr radius and the particle size distribution of $\pm 0.8 \mathrm{~nm}$ is comparable to the standard deviation of $\pm 0.7 \mathrm{~nm}$ from PbSPVA coatings ${ }^{21}$, no fine structured absorption spectrum was observed. The absence of the fine absorption structure is possibly caused by the surface disorder due to the solid precipitation method of $\mathrm{PbS}$ particles in the coatings. The anchoring amino- groups may also have contributed to the introduction of surface disorder on $\mathrm{PbS}$ nanocrystals. This is consistent with the literature results ${ }^{20}$ that $\mathrm{PbS}$ nanoparticles with different mean sizes from 2 to $10 \mathrm{~nm}$ synthesized by the sol-gel processing exhibited no fine-structured absorption peaks.

\section{Relationship Between Optical Band Gap and Mean Nanocrystal Size}

The relationship between optical band gap (i.e., absorption onset) and mean nanocrystal size has been explored theoretically and experimentally in the past years. Al. Éfros and A. Éfros ${ }^{7}$ developed a theoretical model using effective mass approximation. According to Éfros' effective mass approximation theory, optical band gap of nanocrystals will be enlarged with decreasing size. In the case of strong quantum confinement effect, such as $\mathrm{PbS}$ QDs, the particle dimension is much less than twice the Bohr radius. Therefore, optical band gap of the strong quantum confined QDs can be deduced by the following equation: ${ }^{7}$

$$
\mathrm{E}=\mathrm{E}_{\mathrm{g}}+\frac{\hbar^{2} \pi^{2}}{2 \mu \mathrm{R}^{2}}
$$

where $\mathrm{E}$ is the optical band gap of QDs, $\mathrm{E}_{\mathrm{g}}$ the band gap of the corresponding bulk semiconductor crystal, $\hbar$ the Planck's constant divided by $2 \pi, \mu=\mathrm{m}_{\mathrm{e}} \cdot \mathrm{m}_{\mathrm{h}} /\left(\mathrm{m}_{\mathrm{e}}+\mathrm{m}_{\mathrm{h}}\right)$, where $m_{e}$ and $m_{h}$ are the effective masses of the electron and the hole, $\mathrm{R}<<\mathrm{R}_{\mathrm{h}}$ and $\mathrm{R}<<\mathrm{R}_{\mathrm{e}}$, where $\mathrm{R}$ the particle radius, $R_{e}$ and $R_{h}$ the radii of the electron and the hole. As a result, theoretically, the threshold energy of QDs is directly proportional to the reciprocal square of the nanocrystal radius.

However, this theory only approximately agrees with experimental data in the size region larger than $10 \mathrm{~nm}$. When $\mathrm{PbS}$ nanocrystal size is less than $10 \mathrm{~nm}$, the ob- 


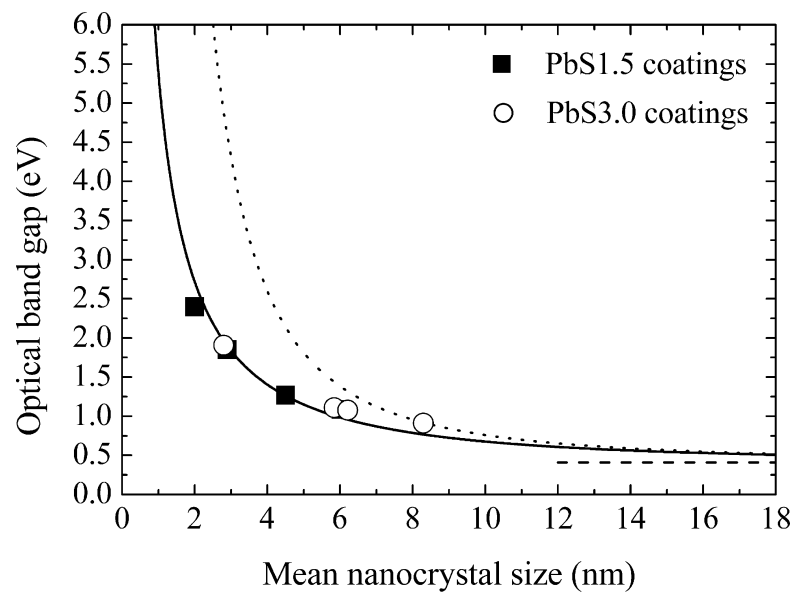

Fig. 6. Relationship between optical band gap and mean nanocrystal size from PbS1.5 and PbS3.0 coatings compared to Efros' effective mass approximation theory (dotted line) and Wang's hyperbolic band model (solid line) along with the optical band gap of bulk PbS crystals (dashed line).

served optical band gap is usually much less than the calculated value from Éfros' theory. The breakdown of this theory is mainly due to the neglect of the size-dependent Coulomb interaction between nanocrystals.

Wang, et al. ${ }^{42}$ proposed a hyperbolic band model in which the size-dependent Coulomb interaction was taken into account:

$$
\Delta \mathrm{E}=\left[\mathrm{E}_{\mathrm{g}}^{2}+\frac{2 \hbar^{2} \mathrm{E}_{\mathrm{g}}(\pi / \mathrm{R})^{2}}{\mathrm{~m}^{*}}\right]^{1 / 2}
$$

where $\Delta \mathrm{E}$ is the optical band gap of QDs, $\mathrm{E}_{\mathrm{g}}$ the band gap of corresponding bulk semiconductor crystals, $\hbar$ the Planck's constant divided by $2 \pi, \mathrm{m}^{*}$ the effective mass taken as $\mathrm{m}^{*}=0.085 \mathrm{~m}, \mathrm{~m}_{\mathrm{e}}$ the mass of a free electron, and $\mathrm{R}$ the radius of $\mathrm{PbS}$ nanocrystals. Wang, et al. ${ }^{42} \mathrm{dem}-$ onstrated that their experimental data fit well with the hyperbolic band model for $\mathrm{PbS}$ nanocrystals larger than $2.5 \mathrm{~nm}$. Eq. (2) is plotted in Fig. 6 along with the Éfros' effective mass approximation theory (Eq. (1)). These theories are compared to our experimental data from $\mathrm{PbS}$ nanoparticles in PbS1.5 and PbS3.0 coatings, along with the band gap of $0.41 \mathrm{eV}$ of bulk PbS crystals.

It is clearly shown from Fig. 6 that the breakdown of Éfros' theory starts from $\mathrm{PbS}$ nanoparticles smaller than about $10 \mathrm{~nm}$. This is consistent with CdSe nanocrystals whose relationship between optical band gap and nanocrystal size does not fit the effective mass approxi-

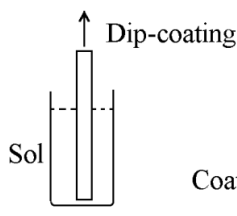

(a)

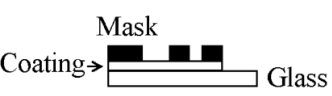

(b)

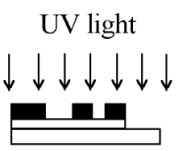

(c)

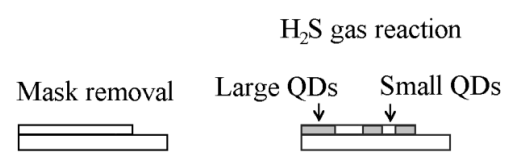

(d) (e)

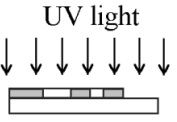

(f)
Fig. 7. Process flow for imaging application of $\mathrm{PbS}$ nanocomposite coatings: (a) dip-coating from a sol to form solgel-derived coatings on glass substrates; (b) partially mask the coatings; (c) pre-photo-polymerization in Beltron UV lamp system; (d) mask removal; (e) react with $\mathrm{H}_{2} \mathrm{~S}$ gas in a sealed container at $25^{\circ} \mathrm{C}$ for $1 \mathrm{hr}$; (f) full polymerization.

mation theory at sizes less than $8 \mathrm{~nm} .{ }^{9}$ In addition, Mahamuni, et al. ${ }^{43}$ also found a discrepancy between experimental data and effective mass approximation theory for $\mathrm{ZnS}$ quantum dots. In Fig. 6, the experimental data are in good agreement with Wang's hyperbolic band model almost in the entire region of less than $18 \mathrm{~nm}$. The experimental data of $\mathrm{PbS}$ nanocrystals in sol-gel-derived silica glass agreed with Wang's model but not Éfros' theory. ${ }^{20}$ The results also indicate a strong Coulomb interaction between QDs when their size becomes smaller. It has been shown that when particle size decreases, the band gap is enlarged, leading to a change in particle color. After the particle size becomes smaller than $4 \mathrm{~nm}$, the band gap increases rapidly. Fig. 6 also reveals that $\mathrm{PbS}$ QDs in $\mathrm{PbS3.0}$ coatings have larger crystal size and smaller band gap than those of PbS1.5 coatings while using the same pre-photo-polymerization conditions.

\section{Imaging Application of PbS Nanocomposite Coatings}

According to the above results, $\mathrm{PbS}$ nanocrystal size changes with UV energy for pre-photo-polymerization and coating composition. During these experiments, a single sample is exposed to certain UV energy for pre-photopolymerization, yielding a single color on the entire sample. In order to create two or more colors in one sample, a mask is utilized on a sample to block UV exposure to the coating. The mask used can be anything that blocks UV, such as paper, UV-absorbing plastics, aluminum foil or sheet, or slide glass, etc. Some areas on the 
mask are open in order to let UV light pass through. The open areas in the mask can be images or letters, etc. The process flow of imaging application of $\mathrm{PbS}$ nanocomposite coatings is schematically illustrated in Fig. 7.

In Fig. 7a, a coating was obtained on a slide glass substrate by a dip-coating process from a sol as described earlier. After drying the coating at room temperature for more than $30 \mathrm{~min}$, the coating was covered with a mask of an image or letters (Fig. 7b). Thereafter, the coating covered with mask materials was exposed to UV light on a moving belt in the Beltron UV lamp system (Fig. 7c). The UV energy was chosen as $4.9 \mathrm{~J} \cdot \mathrm{cm}^{-2}$ for this application. During this step, the part of the coating covered with mask materials wasn't exposed to UV light. In contrast, the part of coating not covered with the mask was exposed to UV light. After UV exposure, the part covered with mask materials was not polymerized and solidified, and vice versa. The next step was to react with $\mathrm{H}_{2} \mathrm{~S}$ gas to precipitate $\mathrm{PbS}$ nanocrystals in the coating. The partially pre-photo-polymerized coating was reacted to $\mathrm{H}_{2} \mathrm{~S}$ gas in a sealed container for $1 \mathrm{hr}$ at room temperature (Fig. 7e). During the reaction, the part initially covered with the mask gradually became deep brown in color, while the other part became bright yellow in color. The reaction stopped after $1 \mathrm{hr}$ by removing the sample from the $\mathrm{H}_{2} \mathrm{~S}$ gas atmosphere. The sample exhibited two different colors, one deep brown with large $\mathrm{PbS}$ nanocrystals, and the other bright yellow with small $\mathrm{PbS}$ nanocrystals. A vivid image appeared in the $\mathrm{PbS}$ nanocomposite coatings. The image can be both positive and negative depending on the masks. In addition, the resolution of $\mathrm{PbS}$ nanocomposite coatings can be extremely high depending on mask techniques. The PbS nanostructure coatings may show three or more colors with a mask having different degrees of UV transmittance. The sample was then exposed to UV light with $4.9 \mathrm{~J} \cdot \mathrm{cm}^{-2} \mathrm{UV}$ energy for final photo-polymerization (Fig. 7f).

An actual sample of structured image of "INM" in PbS1.5 coatings on slide glass is illustrated in Fig. 8. An aluminum mask with "INM" was used to cover the asdip-coated coatings during pre-photo-polymerization. After reacting with $\mathrm{H}_{2} \mathrm{~S}$ gas for $1 \mathrm{hr}$ at room temperature, $\mathrm{PbS}$ nanoparticles were formed in the coatings. Finally, the PbS1.5 coatings were cured again by $4.9 \mathrm{~J} \cdot \mathrm{cm}^{-2} \mathrm{UV}$ energy in the UV system. Here, the part of the coatings covered with aluminum had a brown color while the other part without aluminum (letters INM) covering was bright yellow. This structured image "INM" is caused by different $\mathrm{PbS}$ nanocrystal sizes.

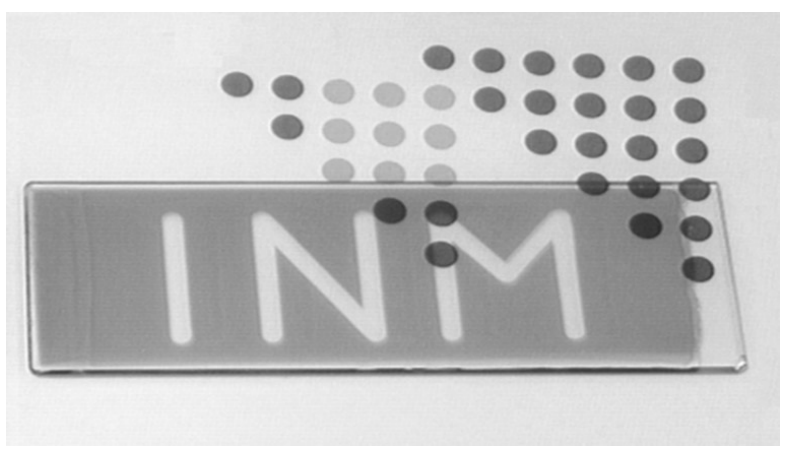

Fig. 8. Image of "INM" in PbS nanocomposite coatings: The partially masked PbS1.5 coating was first pre-photo-polymerized with a UV energy of $4.9 \mathrm{~J} \cdot \mathrm{cm}^{-2}$, reacted with $\mathrm{H}_{2} \mathrm{~S}$ gas for $1 \mathrm{hr}$ at $25^{\circ} \mathrm{C}$, and then was fully polymerized with a UV energy of 4.9 $\mathrm{J} \cdot \mathrm{cm}^{-2}$. The dots in this image are from a letterhead. They are not from PbS nanocomposite coatings.

\section{Conclusions}

$\mathrm{PbS}$ nanocrystals with different crystal sizes have been precipitated in sol-gel-derived nanocomposite coatings by controlling UV energy for pre-photo-polymerization and coating composition. The growth of $\mathrm{PbS}$ nanocrystals in the nanocomposite coatings depends on the degree of matrix polymerization, i.e., the degree of solidification of the sol-gel-derived coatings. As a result, the optical property and coating color change significantly with tunable nanocrystal size, resulting from the quantum confinement effect. A process for the imaging application of $\mathrm{PbS}$ nanocomposite coatings was developed by a masking technique utilizing the size-dependent optical property.

\section{Acknowledgments}

S. W. Lu would like to sincerely thank Dr. Martin Mennig, Dr. Ulrich Sohling, Dr. Qiwu Xing, and Prof. Lisong Hou for extensive and useful discussions and Dr. Thomas Krajewski for high resolution TEM investigation.

\section{References}

1. L. Brus, "Chemical Approaches to Semiconductor Nanocrystals," J. Phys. Chem. Solids, 59 [4] 459-65 (1998).

2. A. P. Alivisatos, "Semiconductor Clusters, Nanocrystals, and Quantum Dots," Science, 271 933-7 (1996).

3. A. P. Alivisatos, "Perspectives on the Physical Chemistry of Semiconductor Nanocrystals," J. Phys. Chem., 100 13226-39 (1996).

4. A. P. Alivisatos, "Semiconductor Nanocrystals," MRS Bull., 20 [8] 23-32 (1995).

5. A. Henglein, "Small-Particle Research: Physicochemical Properties of Extremely Small Colloidal Metal and Semiconductor Particles," Chem. Rev., 89 1861-73 (1989). 
6. M. Kuno, J. K. Lee, B. O. Dabbousi, F. V. Mikulec and M. G. Bawendi, "The Band Edge Luminescence of Surface Modified CdSe Nanocrystallites: Probing the Luminescing State," J. Chem. Phys., 106 [23] 9869-82 (1997).

7. Al. L. Éfros and A. L. Éfros, "Interband Absorption of Light in a Semiconductor Sphere," Sov. Phys. Semicond., 16 [7] 772-5 (1982).

8. A. I. Ekimov and A. A. Onushchenko, "Quantum Size Effect in the Optical Spectra of Semiconductor Microcrystals," Sov. Phys. Semicond., 16 [7] 775-8 (1982).

9. C. B. Murray, D. J. Norris and M. G. Bawendi, "Synthesis and Characterization of Nearly Monodisperse CdE (E = S, Se, Te) Semiconductor Nanocrystallites," J. Am. Chem. Soc., 115 8706-15 (1993).

10. V. I. Klimov, D. W. McBranch, C. A. Leatherdale and M. G. Bawendi, "Electron and Hole Relaxation Pathways in Semiconductor Quantum Dots," Phys. Rev. B, 60 [19] 13740-9 (1999).

11. T. Torimoto, H. Kontani, Y. Shibutani, S. Kuwabata, T. Sakata, H. Mori and H. Yoneyama, "Characterization of Ultrasmall CdS Nanoparticles Prepared by the Size-Selective Photoetching Technique," J. Phys. Chem. B, 105, 683845 (2001).

12. M. Shim, C. Wang, D. J. Norris and P. Guyot-Sionnest, "Doping and Charging in Colloidal Semiconductor Nanocrystals," MRS Bull., 26 [12] 1005-8 (2001).

13. H. Weller, "Quantized Semiconductor Particles: A Novel State of Matter for Materials Science," Adv. Mater., 5 [2] 88-95 (1993).

14. P. T. Guerreiro, S. Ten, N. F. Borrelli, J. Butty, G. E. Jabbour and N. Peyghambarian, "PbS Quantum-Dots Doped Glasses as Saturable Absorbers for Mode Locking of a Cr:Forsterite Laser," Appl. Phys. Lett., 71 [12] 1595-7 (1997).

15. A. A. Patel, F. Wu, J. Z. Zhang, C. L. Torres-Martinez, R. K. Mehra, Y. Yang and S. H. Risbud, "Synthesis, Optical Spectroscopy and Ultrafast Electron Dynamics of PbS Nanoparticles with Different Surface Capping," J. Phys. Chem. B, 104 11598-605 (2000).

16. V. C. Colvin, M. C. Schlamp and A. P. Alivisatos, "Light-Emitting Diodes Made from Cadmium Selenide Nanocrystals and a Semiconducting Polymer," Nature, 370 354-7 (1994).

17. J. L. Machol, F. W. Wise, R. C. Patel and D. B. Tanner, "Vibronic Quantum Beats in PbS Microcrystallites,” Phys. Rev. B, 48 [4] 2819-22 (1993).

18. J. M. Nedeljkovic, R. C. Patel, P. Kaufman, C. Joyce-Pruden and N. O’Leary, "Synthesis and Optical Properties of Quantum-Size Metal Sulfide Particle in Aqueous Solution," J. Chem. Edu., 70 [4] 342-4 (1993).

19. S. Gallardo, M. Gutitrrez, A. Henglein and E. Janata, "Photochemistry and Radiation Chemistry of Colloidal Semiconductors, 34. Properties of Q-PbS," Ber. Bunsenges. Phys. Chem., 93 1080-90 (1989).

20. M. Nogami, K. Nagasaka and K. Kotani, "Microcrystalline PbS Doped Silica Glasses Prepared by the Sol-Gel Process," J. Non-Cryst. Solids, 126 87-92 (1990).

21. S. W. Lu, U. Sohling, M. Mennig and H. Schmidt, "Nonlinear Optical Properties of Lead Sulfide Nanocrystals in Polymeric Coatings," Nanotechnology, 13 [5] 669-73 (2002).

22. L. Banyai, Y. Z. Hu, M. Lindberg and S. W. Koch, "Third-Order Optical Non-Linearities in Semiconductor Microstructures," Phys. Rev. B, 38 814253 (1988).

23. A. Martucci, J. Fick, J. Schell, G. Battaglin and M. Guglielmi, "Microstructural and Nonlinear Optical Properties of Silica-Titania Sol-Gel Film Doped with PbS Quantum Dots," J. Appl. Phys., 86 [1] 79-87 (1999).

24. I. Moriguchi, K. Hanai, Y. Teraoka, S. Kagawa, S. Yamada and T. Matsuo, "Third Harmonic Generation from Quantum-State PbS Embedded in Langmuir-Blodgett Film Matrix," Jpn. J. Appl. Phys. Part 2, 34 L323-5 (1995).
25. K. Wundke, J. Auxier, A. Schulzgen, N. Peyghambarian and N. F. Borrelli, "Room-Temperature Gain at $1.3 \mathrm{~mm}$ in PbS-Doped Glasses," Appl. Phys. Lett., 75 [20] 3060-2 (1999).

26. M. Ando, K. Kadono, M. Haruta, T. Sakaguchi and M. Miya, "Large 3rdOrder Optical Nonlinearities in Transition-Metal Oxides," Nature, 374 625-7 (1995).

27. L. Bakueva, S. Musikhin, M. A. Hines, T.-W. F. Chang, M. Tzolov, G. D. Scholes and E. H. Sargent, "Size-Tunable Infrared (1000-1600 nm) Electroluminescence from PbS Quantum Dot Nanocrystals in a Semiconducting Polymer,” Appl. Phys. Lett., 82 [17] 2895-97 (2003).

28. N. F. Borrelli and D. W. Smith, "Quantum Confinement of PbS Microcrystals in Glass,” J. Non-Cryst. Solids, 180 25-31 (1994).

29. E. V. Kolobkova, A. A. Lipovskii, V. D. Petrikov and V. G. Melekhin, "Fluorophosphate Glasses with Quantum Dots Based on Lead Sulfide," Glass Phys. \& Chem., 28 [4] 251-5 (2002).

30. F. E. Kruis, K. Nielsch, H. Fissan, B. Rellinghaus and E. F. Wasserman, "Preparation of Size-Classified PbS Nanoparticles in the Gas Phase," Appl. Phys. Lett., 73 [4] 547-9 (1998).

31. K. K. Nanda, F. E. Kruis, H. Fissan and M. Acet, "Band-Gap Tuning of PbS Nanoparticles by In-Flight Sintering of Size Classified Aerosols," J. Appl. Phys., 91 [4] 2315-21 (2002).

32. M. Kowshik, W. Vogel, J. Urban, S. K. Kulkarni and K. M. Paknikar, "Microbial Synthesis of Semiconductor PbS Nanocrystallites," Adv. Mater, 14 [11] 8158 (2002).

33. A. Martucci, P. Innocenzi, J. Fick and J. D. Mackenzie, "Zirconia-Ormosil Films Doped with PbS Quantum Dots," J. Non-Cryst. Solids, 244 55-62 (1999).

34. A. Raab and G. Springholz, "Controlling the Size and Density of Self-Assembled PbSe Quantum Dots by Adjusting the Substrate Temperature and Layer Thickness," Appl. Phys. Lett., 81 [13] 2457-9 (2002).

35. L. Manna, E. C. Scher and A. P. Alivisatos, "Synthesis of Soluble and Processable Rod-, Arrow-, Teardrop-, and Tetrapod-Shaped CdSe Nanocrystals," J. Am. Chem. Soc., 122 12700-6 (2000).

36. D. Xu, G. Guo, Y. Guo, Y. Zhang and L. Gui, "Nanocrystal Size Control by Bath Temperature in Electrodeposited CdSe Thin Films," J. Mater. Chem., 13 360-4 (2003).

37. W. J. Parak, D. Gerion, T. Pellegrino, D. Zanchet, C. Micheel, S. C. Williams, R. Boudreau, M. A. Le Gros, C. A. Larabell and A. P. Alivisatos, "Biological Applications of Colloidal Nanocrystals," Nanotechnology, 14 R15-27 (2003).

38. N. Desilles, L. Lecamp, P. Lebaudy and C. Bunel, "Gradient Structure Materials from Homogeneous System Induced by UV Photopolymerization,” Polymer, 44 6159-67 (2003).

39. T. Gacoin, J. B. Boilot, M. Gandais, C. Ricolleau and M. Chamarro, "Transparent Sol-Gel Matrices Doped with Quantum Sized PbS Particles," Mater. Res. Soc. Symp. Proc., 358 247-52 (1995).

40. C. Ricolleau, M. Gandais, T. Gacoin and J. P. Boilot, "Correlation between Structural and Optical Properties of PbS Nanocrystals," J. Cryst. Growth, 166 769-73 (1996).

41. D. U. Saenger, "Theory of the Optical Response of a Dilute Ensemble of Semiconducting Nanoparticles Embedded in a Dielectric Matrix," Phys. Rev. $B, 54$ [20] 14604-17 (1996).

42. Y. Wang, A. Suna, W. Wahler and R. Kasowski, "PbS in Polymers. From Molecules to Bulk Solids," J. Chem. Phys., 87 [12] 7315-22 (1987).

43. S. Mahamuni, A. A. Khosravi, M. Kundu, A. Kshirsagar, A. Bedekar, D. B. Avasare, P. Singh and S. K. Kulkarni, "Thiophenol-Capped ZnS Quantum Dots," J. Appl. Phys., 73 [10] 5237-40 (1993). 